\title{
Antineoplastic Biological Agent
}

National Cancer Institute

\section{Source}

National Cancer Institute. Antineoplastic Biological Agent. NCI Thesaurus. Code C129821.

Any agent that has a biological nature, such as agents containing living organisms, derived from living organisms, or comprised of ex vivo synthesized analogs of substances derived from living organisms, and that exerts antineoplastic activity. 